\title{
Ensayos acelerados de resistencia del hormigón
}

\author{
R. KRISHNA IYER y N. SUKESAN NAIR
}

The Indian Concrete Journal, vol. 51, núm. 11, págs. 334-341, noviembre 197ð

Las normas para proyectar las estructuras de hormigón se basan, en cuanto a calidad se refiere, en los resultados del ensayo de la compresión de probetas preparadas y curadas en condiciones normalizadas, rotas a 28 días de edad. Este largo plazo causa dificultades pues sus indicaciones se conocen cuando ya han sido colocadas grandes cantidades de hormigón; esto es trágico si el resultado acusa una calidad defectuosa.

Se impone utilizar métodos acelerados que permitan aplicar inmediatos correctivos en casos necesarios. Los métodos acelerados permiten, además, conocer rápidamente si la proporción proyectada alcanza las resistencias requeridas.

Los autores estudian tres modos de operar, limitándose principalmente al estudio de la relación entre los resultados obtenidos para la resistencia a la compresión alcanzada por el métodol normalizado a 28 días y la que arrojan los ensayos acelerados, por el hormigón preparado con cemento portland ordinario.

Según ellos el ensayo acelerado debe cumplir las siguientes condiciones:

1) El procedimiento y los utensilios serán relativamente sencillos. El equipo será posible trasladar y montar en la construcción que se vigila.

2) Los resultados del ensayo serán reproducibles y comparables con los obtenidos en otros lugares utilizando el mismo equipo.

3) Los resultados del ensayo deberán obtenerse dentro de las 24 a 28 horas desde que se prepare el hormigón y para finalizarlo debe exigir un mínimo de trabajo adicional.

4) La relación entre el valor acelerado y el del ensayo a 28 días deberá poder aplicarse a hormigones de un amplio rango de resistencias. Es de desear que la relación mencionada no aparezca influenciada por el uso de aditivos usados comúnmente.

Los métodos de resistencias aceleradas imponen un curado acelerado de las probetas. Esto se consigue acelerando la velocidad de hidratación del cemento que así endurece más rápidamente y alcanza una resistencia suficiente en un intervalo de tiempo más corto. 
Los siguientes dos métodos conducen a resultados repetibles y reproducibles:

a) Aplicación de calor desde el exterior usualmente mediante agua caliente.

b) Retención del calor producido por la hidratación del cemento aplicando un aislamiento conveniente.

Al primer grupo pertenece el método del agua caliente y el del agua hirviente.

El método del agua caliente satisface las condiciones de sencillez y proporciona resultados dentro de 36 horas. Inicialmente se aplicó agua a $35^{\circ} \mathrm{C}$; el incremento de la resistencia fue relativamente pequeño. Más tarde la temperatura aplicada fue de $55^{\circ} \mathrm{C}$ y así quedó aceptado por el Comité Británico de Ensayos Acelerados.

En el método con agua hirviendo, las probetas y sus moldes se sumergen en agua calentada previamente a $60^{\circ} \mathrm{C}$; a continuación se hace hervir el agua durante 7 horas. Seguidamente se extraen las probetas y, después de enfriarlas durante 1 hora, se las rompe a compresión. El método se ha modificado colocando las probetas en agua hirviendo manteniendo la ebullición durante 3 horas y media; luego se enfriani durante 1 hora y se rompen a compresión.

\section{ESTUDIOS PREVIOS}

T. N. Akroyd ensayó varios métodos y concluyó en que el método de "ebullición modificado" resulta el más eficiente y proporciona mejores resultados que los otros (1).

Las investigaciones realizadas en el Instituto Central de Investigaciones de la Construcción han conducido a la conclusión de que el método que usa agua a $55^{\circ} \mathrm{C}$, adoptado por el Comité Inglés de Ensayos Acelerados, proporciona resultados suficientemente dignos de confianza.

Investigaciones realizadas durante la construcción de la presa de Idukki en el Estado de Kezala condujeron a la adopción del método "ebullición modificado" recomendado por Malhotra y Zoldners (2).

El método por retención del calor producido en la hidratación requiere un plazo de curado más largo. Los resultados son muy afectados por la temperatura del hormigón al finalizar el amasado; es poco lo que se aumenta la resistencia cuando se ensayan cementos de poco calor de hidratación.

\section{MATERIALES Y EQUIPOS UTILIZADOS}

Cemento: Portland ordinario.

Arido fino: Arena de río.

Arido grueso: Granito machacado con $20 \mathrm{~mm}$ de tamaño mínimo.

Agua: La usada para beber, de la red ciudadana.

Probetas: Cubos de hormigón compactados por vibración y obtenidos en hormigonadora de 142 litros. Los cubos, de $15 \mathrm{~cm}$ de arista, se enmoldaron en moldes de hierro colado. 
Tanque para el curado acelerado: De acero, con las dimensiones: $93 \times 41 \times 55$ centímetros. Aislado exeriormente con contrachapado de madera.

El agua se llevó a $100^{\circ} \mathrm{C}$ en 2 horas y media mediante tres elementos eléctricos de calefacción cada uno de $2 \mathrm{~kW}$.

Se prepararon 6 cubos: 3 para el curado acelerado y otros 3 para el ensayo normalizado a 28 días.

Después de llenos y vibrados los moldes, se les mantuvo durante 24 horas en ambiente húmedo a la temperatura del laboratorio.

La rotura, después del curado acelerado, se realizó en una prensa de 200 t.

El estudio se limitó a la determinación de la relación entre la resistencia obtenida con el método acelerado y la alcanzada según las normas a los 28 días. Estos valores se llevaron a un sistema de coordenadas rectangulares cuyos ejes fueron:

- Abscisas: La resistencia alcanzada normalmente a 28 días.

- Ordenadas: El cociente $r=\frac{\text { resistencias aceleradas }}{\text { resistencias a } 28 \text { días }}$

Se obtuvo una línea recta cuya ecuación fue: $r=0,2955+12 \times 10^{-5} \cdot \sigma$.

Donde $\sigma$ es la resistencia esperada para cada composición del hormigón y alcanzada a los 28 días en condiciones usuales en una estructura.

Con igual procedimiento se obtuvo la ecuación que une los valores de $r$ y de la relación agua/cemento $=w \cdot r=0,5 w-0,1$.

El conocimiento del valor $r$ para cada tipo de hormigón permite conocer el valor real que alcanzará la resistencia a la compresión a los 28 días.

\section{O N C L U S I O N E S}

1. ${ }^{a} \quad$ La resistencia con el curado acelerado es, aproximadamente, el 25 a $35 \%$ de la resistencia alcanzada según procedimiento normal a los 28 dỉas.

2. ${ }^{\text {a }}$ Para hormigones de los tipos 100 a 350, el valor $r$ está en relación lineal con la resistencia normal a los 28 días, según la ecuación: $r=0,2955+12 \times 10^{-5} \sigma$.

3. ${ }^{a}$ Cuando la resistencia obtenida con el curado acelerado se conoce, se puede predecir la resistencia normal a 28 días, con una certeza del $80 \%$. La ecuación es:

$$
R_{28 \text { diais }}=2,068 R_{\text {acelerada }}+97,46 \text {. }
$$

\section{R E F E R E N C I A S}

(1) Akroyd, T. N.: Paper n..$^{\circ}$ 6.441. Proceedings of the Institution of Civil Engineers, V-1961, vol. 19, págs. 1-28.

(2) Nalhotra, V. M. y Zoldners: Journal of the American Concrete Institute, V-1970. Proc. vol. 67, páginas $424-434$.

P. García de Paredes 


\section{CUADRO 1}

Clasificación de los métodos acelerados

\begin{tabular}{|c|c|c|c|c|c|}
\hline Procedimiento & $\begin{array}{l}\text { Medio de cura- } \\
\text { do acelerado }\end{array}$ & $\begin{array}{l}\text { Temperatura de } \\
\text { curado acelerado }\end{array}$ & $\begin{array}{l}\text { Edad a la cual } \\
\text { se inicia el cu- } \\
\text { rado acelerado }\end{array}$ & $\begin{array}{c}\text { Duración del } \\
\text { curado } \\
\text { acelerado }\end{array}$ & $\begin{array}{c}\text { Edad del } \\
\text { ensayo }\end{array}$ \\
\hline Agua caliente & Agua & $55^{\circ} \mathrm{C}$ & $\begin{array}{l}\text { Inmediatamente } \\
\text { cespués del } \\
\text { amasado }\end{array}$ & $\begin{array}{l}231 / 2 \text { horas } \\
\pm 30 \mathrm{~min}\end{array}$ & $\begin{array}{l}26 \text { horas } \\
\pm 15 \mathrm{~min}\end{array}$ \\
\hline $\begin{array}{l}\text { Método de ebu- } \\
\text { llición }\end{array}$ & Agua & $100^{\circ} \mathrm{C}$ & $\begin{array}{l}30 \text { minutos } \\
\text { después del } \\
\text { amasado }\end{array}$ & 7 horas & $\begin{array}{l}8 \text { horas } \\
\pm 30 \mathrm{~min}\end{array}$ \\
\hline $\begin{array}{l}\text { Método de ebu- } \\
\text { llicíón modifi- } \\
\text { cado }\end{array}$ & Agua & $100^{\circ} \mathrm{C}$ & $\begin{array}{l}24 \text { horas } \\
\text { después del } \\
\text { amasado }\end{array}$ & $\begin{array}{l}31 / 2 \text { roras } \\
\pm 15 \text { min. }\end{array}$ & $\begin{array}{l}281 / 2 \text { horas } \\
\pm 15 \mathrm{~min}\end{array}$ \\
\hline
\end{tabular}

